\title{
Potencial genético de progênies de feijão-caupi segregantes quanto ao tipo da inflorescência
}

Fábio Ribeiro Barros ${ }^{(1)}$, Clodoaldo José da Anunciação Filho(2), Maurisrael de Moura Rocha(2), José Airton Rodrigues Nunes ${ }^{(3)}$, Kaesel Jackson Damasceno e Silva(2), Francisco Rodrigues Freire Filho ${ }^{(2)}$

e Valdenir Queiroz Ribeiro(2)

(1) Universidade Federal Rural de Pernambuco, Departamento de Agronomia, Rua Dom Manoel de Medeiros, s/no, Dois Irmãos, CEP 52171-900 Recife, PE. E-mail: fabio@agronomo.eng.br, cjoseufrpe@hotmail.com (2)Embrapa Meio-Norte, Caixa Postal 01, CEP 64006-220 Teresina, PI. E-mail: mmrocha@cpamn.embrapa.br, kaesel@cpamn.embrapa.br, freire@cpamn.embrapa.br, valdenir@cpamn.embrapa.br ${ }^{(3)}$ Universidade Federal de Lavras, Departamento de Biologia, Caixa Postal 3037, CEP 37200-000 Lavras, MG. E-mail: jarnunes@dbi.ufla.br

Resumo - O objetivo deste trabalho foi avaliar o potencial genético produtivo de progênies de feijão-caupi (Vigna unguiculata) segregantes quanto ao tipo da inflorescência. Foram avaliadas 68 progênies $\mathrm{F}_{4}$ obtidas dos retrocruzamentos: (TV x 5058-09C x Cacheado-roxo) x TV x 5058-09C e (AU94-MOB-816 x Cacheado-roxo) $\mathrm{x}$ AU94-MOB-816, com os genitores. Dois experimentos foram conduzidos no delineamento de blocos ao acaso, tendo-se avaliado 17 progênies, com quatro repetições, em parcelas subdivididas quanto à inflorescência: simples e composta. A análise estatística foi realizada por modelos mistos via procedimento REML/BLUP. As estimativas das variâncias genéticas foram significativas para todos os caracteres estudados. Os caracteres comprimento do pedúnculo, número médio de vagens por pedúnculo e floração inicial apresentaram alta variabilidade e expressão do componente genético para a inflorescência composta. As progênies de inflorescência simples apresentam potencial genético produtivo similar às progênies de inflorescência composta. As progênies resultantes do retrocruzamento (AU94-MOB-816 x Cacheado-roxo) x AU94-MOB-816 são promissoras como estratégia para aumentar os níveis atuais de produtividade do feijão-caupi.

Termos para indexação: Vigna unguiculata, melhoramento de feijão-caupi, produtividade, REML/BLUP, seleção.

\section{Genetic potential of segregating cowpea progenies regarding inflorescence type}

\begin{abstract}
The objective of this work was to evaluate the genetic yield potential of segregating cowpea progenies regarding inflorescence type. Sixty-eight $\mathrm{F}_{4}$ progenies obtained from the backcrosses (TV x 5058-09C x Curly-purple) x TV x 5058-09C, and (AU94-MOB-816 x Curly-purple) x AU94-MOB-816, with parents, were evaluated. Two experiments were carried out in a randomized complete block design with 17 progenies and four replicates, in a split-plot arrangement regarding inflorescence: simple and composite. The statistical analysis was carried out by mixed models via REML/BLUP procedure. The estimates of genetic variance were significant for all evaluated traits. The traits peduncle length, average number of pods per peduncle, and initial flowering showed high variability and expression of the composite inflorescence genetic component. Progenies with simple inflorescence show similar genetic yield potential to the progenies with composite inflorescence. The progenies resulting from the backcrosses (AU94-MOB-816 x Curly-purple) x AU94-MOB-816 are promising as a strategy to increase the current levels of grain yield in cowpea.
\end{abstract}

Index terms: Vigna unguiculata, cowpea breeding, yield, REML/BLUP, selection.

\section{Introdução}

O feijão-caupi [Vigna unguiculata (L.) Walp.] possui plasticidade fenotípica e alta variabilidade genética, o que o torna adaptado a várias condições de clima e solo (Freire Filho et al., 2005). Embora o Brasil seja o terceiro maior produtor mundial de feijão-caupi (Timko \& Singh, 2008), ainda há um deficit na oferta deste alimento (Nakamae, 2004).
Entre os avanços proporcionados a esta cultura pelo melhoramento genético, pode-se citar o desenvolvimento de cultivares mais precoces e uniformes; resistentes e tolerantes a estresses, como vírus, seca e altas temperaturas; resistentes ao acamamento, com porte semiereto, inserção das vagens acima da folhagem e maturação mais uniforme das vagens; e com maior estabilidade e adaptabilidade a diferentes ecossistemas

Pesq. agropec. bras., Brasília, v.46, n.2, p.182-189, fev. 2011 
das regiões Norte e Nordeste do Brasil (Freire Filho et al., 2008, 2009).

A biologia reprodutiva da espécie constitui um aspecto importante do seu potencial produtivo. O tipo de inflorescência, entre outros componentes, figura como um dos fatores mais influentes sobre a produção. O feijão-caupi caracteriza-se por, em geral, possuir uma inflorescência simples, diferentemente de outras espécies da família das leguminosas, como o feijão-comum (Phaseolus vulgaris L.).

A variabilidade genética para o caractere tipo de inflorescência é bastante reduzida e praticamente não tem sido explorada para fins de melhoramento genético. No Brasil, há conhecimento de apenas um acesso de inflorescência composta, a cultivar Cacheado, coletado no Piauí e descrito por Araújo et al. (1981). Segundo os autores, essa cultivar apresenta alto potencial de produção, e pode produzir até oito vagens por inflorescência. De acordo com Machado et al. (2007), a característica inflorescência composta altera morfologicamente a parte reprodutiva da planta, o que provoca bifurcações a uma certa altura do pedúnculo, e novos segmentos que, por sua vez, produzirão flores e frutos.

Em estudos de controle genético da inflorescência em feijão-caupi, foram identificados dois genes recessivos responsáveis pela expressão da inflorescência composta, o gene $c i$ (Sen \& Bhowal, 1961) e o gene $b p$ (Fawole \& Afolabi, 1983). Machado et al. (2007), ao estudar o controle genético para a inflorescência composta na cultivar Cacheado, concluíram que a herança é monogênica recessiva. Rocha et al. (2009), ao estudar o controle genético do comprimento do pedúnculo simples, observaram que a herança é oligogênica e a ação gênica é predominantemente aditiva. Sousa (2008), ao investigar a herança do comprimento do pedúnculo ramificado em progênies $\mathrm{F}_{2}$ de feijão-caupi, com inflorescência simples e composta, quanto à produção e aos seus componentes, chegou à conclusão de que o comprimento do pedúnculo ramificado tem controle genético oligogênico e aditivo.

Diferenças significativas entre progênies de inflorescência simples e composta foram encontradas para vários caracteres de produção e seus componentes (Sousa, 2008). Segundo Machado et al. (2007), a transferência do gene que controla a inflorescência composta para genótipos com diferentes tipos de arquitetura de planta é importante para se avaliar se o gene produz impacto positivo na produtividade do feijão-caupi. A perspectiva é que a inflorescência composta seja transferida para cultivares comerciais e, com isso, seja possível elevar o patamar de produtividade da espécie (Freire Filho et al., 2009).

O objetivo deste trabalho foi avaliar o potencial genético produtivo de progênies de feijão-caupi segregantes quanto ao tipo da inflorescência.

\section{Material e Métodos}

Foram avaliados três genótipos genitores de feijão-caupi - $\mathrm{P}_{1}$, Cacheado-roxo; $\mathrm{P}_{2}$, (TV x 5058-09C); e $\mathrm{P}_{3}$, AU94-MOB-816 - e 68 progênies $\mathrm{F}_{4}$ resultantes do retrocruzamento 1 (RC1), - [(TV x 5058-09C) $\mathrm{x}$ Cacheado-roxo)] x (TV x 5058-09C) - e do retrocruzamento 2 (RC2) - (AU94-MOB-816 x Cacheado-roxo) x AU94-MOB-816. Os cruzamentos $\mathrm{RC} 1$ e $\mathrm{RC} 2$ e as populações $\mathrm{F}_{1}$ e $\mathrm{F}_{2}$ foram avaliados por Sousa (2008). Em cada população $F_{4}$ resultante de $\mathrm{RC} 1$ e $\mathrm{RC} 2$, foram tomadas aleatoriamente progênies de cinco plantas de inflorescência simples e composta.

Foram instalados dois experimentos ( $\mathrm{RC} 1 \mathrm{e}$ RC2) contíguos de avaliação das progênies de cada população segregante, no campo experimental da Embrapa Meio-Norte, em Teresina, PI, em 2008. Utilizou-se o delineamento experimental de blocos ao acaso com quatro repetições. Os tratamentos, em cada experimento, consistiram de 17 progênies $\mathrm{F}_{4}$ em parcelas subdivididas quanto ao tipo da inflorescência (simples e composta), e três testemunhas (genitores). A subparcela foi constituída de uma fileira de $10 \mathrm{~m}$, e utilizou-se o espaçamento de $1 \mathrm{~m}$ entre as fileiras e $0,5 \mathrm{~m}$ dentro da fileira. Na semeadura, foram utilizadas duas sementes por cova, para assegurar a germinação. Após a germinação, foram feitos o replantio, o desbaste e a identificação das plantas. A subparcela útil foi composta de cinco plantas.

Foram avaliados os seguintes caracteres: floração inicial (FI), a partir da semeadura até o surgimento das primeiras flores; número de pedúnculos com vagem (NPV), expresso pela média do número de pedúnculos com vagens das plantas; comprimento do pedúnculo com vagem (COMPP), média do comprimento dos pedúnculos com vagens; número de vagens por pedúnculo (NVP), média do número de vagens por pedúnculo; comprimento de vagem (COMPV), média de todas as vagens das plantas; peso de 100 grãos 
(P100G); número médio de grãos por vagem (NGV); produção de grãos (PG), obtida após a colheita de todas as plantas da subparcela; e índice de grãos (IG), determinado pela razão entre $\mathrm{PG}$ e o peso das vagens (PV), [(PG/PV)x100], e expresso em percentagem.

$\mathrm{O}$ solo da área experimental era um Argissolo eutrófico. A irrigação suplementar foi feita pelo método de aspersão convencional, com um turno de rega de duas horas a cada dois dias, e aplicação de lâmina de água de $6 \mathrm{~mm}$. O controle das ervas daninhas foi realizado pela aplicação dos herbicidas de pré-emergência à base de S-metolachlor, na dosagem de 1,5 $\mathrm{L} \mathrm{ha}^{-1}$, e por duas capinas. O controle fitossanitário foi efetuado com duas aplicações preventivas de metalaxil-mancozeb, na dosagem de $40 \mathrm{~g} \mathrm{ha}^{-1}$ do produto comercial, para o controle de fungos do solo, e duas aplicações de inseticidas à base de tiametoxam e dimetoato, nas dosagens de $100 \mathrm{~g} \mathrm{ha}^{-1}$ e 1,0 $\mathrm{L} \mathrm{ha}^{-1}$, respectivamente, para o controle de pulgões (Apis cracyvora Koch) e mosca-branca [Bemisia tabaci (Genn.)].

Os dados fenotípicos foram analisados por modelos mistos (Resende, 2002), de acordo com o modelo estatístico,

$$
y_{i j k}=\mu+p_{i}+b_{j}+p b_{i j}+q_{(i) k}+\varepsilon_{i j k},
$$

em que: $\mathrm{y}_{\mathrm{ijk}}$ é a observação da subparcela que recebeu o tratamento genético ik no bloco j; $\mu$ é a constante associada à todas as observações; $p_{i}$ é o efeito aleatório da progênie ou da testemunha i, $p_{\mathrm{i}} \sim \mathrm{N}\left(0, \sigma^{2}\right) ; b_{\mathrm{j}}$ é o efeito aleatório da repetição $j, b_{j} \sim \mathrm{N}\left(0, \sigma^{2}\right) ; p b_{i j}$ é o efeito aleatório da interação progênie ou testemunha i com o bloco j, pb $b_{i j} \sim \mathrm{N}\left(0, \sigma_{\mathrm{pb}}^{2}\right)$; $\mathrm{q}_{(\mathrm{i}) \mathrm{k}}$ é o efeito aleatório da progênie k na progênie $\mathrm{i}, \mathrm{q}_{\mathrm{k}} \sim \mathrm{N}\left(0, \sigma_{\mathrm{q}}^{2}\right)$; e $\varepsilon_{\mathrm{ijk}}$ é o erro experimental aleatório associado às observações $\mathrm{y}_{\mathrm{ijk}}$, $\varepsilon_{\mathrm{ijk}} \sim \mathrm{N}\left(0, \sigma_{\mathrm{e}}^{2}\right)$.

A estimação dos componentes de variância foi realizada pelo método da máxima verossimilhança restrita, REML (Patterson \& Thompson, 1971), e os intervalos de confiança (IC), associados às estimativas de variâncias genéticas e ambientais, foram estimados a partir da expressão (Ramalho et al., 2005):

$$
\operatorname{IC}\left(\sigma^{2}\right)=\mathrm{P}\left[v \sigma_{\mathrm{i}}^{2} / \hat{\sigma}_{\mathrm{i}}^{2} \chi_{(v ; 1-\alpha / 2)}^{2}<\sigma_{\mathrm{i}}^{2}<v \hat{\sigma}_{\mathrm{i}}^{2} / \chi_{(v ; \alpha / 2)}^{2}\right]
$$

em que: $\alpha$ é o nível de significância pré-estabelecido, no caso $\alpha=0,05$; v são os graus de liberdade associados ao componente $\hat{\sigma}_{i}^{2}$, obtidos pela aproximação de
Satterthwaite (1946); e $\chi_{(v ; 1-\alpha / 2)}^{2}$ e $\chi_{(v ; \alpha / 2)}^{2}$ são os quantis da distribuição qui-quadrado, para $v$ graus de liberdade.

Os valores genotípicos das progênies foram preditos pelo procedimento do melhor preditor linear não viesado (BLUP), conforme Henderson (1975). Utilizou-se o teste $\mathrm{t}$, a $5 \%$ de probabilidade, para testar os contrastes entre médias de progênies com inflorescência simples e composta.

As análises foram realizadas pelo procedimento Proc Mixed do programa SAS (SAS Institute, 1999).

\section{Resultados e Discussão}

As estimativas de variâncias genéticas para os caracteres IG, NGV, NPV, P100G e PG, no RC1, e COMPV, IG, NGV, NPV, P100G e PG, no RC2, foram maiores para a inflorescência simples, enquanto as estimativas para os caracteres COMPP, COMPV, FI e NVP, no RC1, e COMPP, FI e NVP, no RC2, foram maiores para a inflorescência composta (Tabela 1). Os caracteres COMPP e PG, nos dois retrocruzamentos, apresentaram diferenças consideráveis na variância genética para a inflorescência composta. As estimativas das variâncias genéticas obtidas neste trabalho foram maiores que as obtidas por Teixeira et al. (2007) nos caracteres PG $(32.409,09)$, IG $(31,37)$, NVP $(2,71)$ e P100G $(6,50)$, em estudo conduzido com genótipos de inflorescência simples.

As estimativas da variância genética e seu respectivo intervalo de confiança, a 95\% de probabilidade, foram significativas (Tabela 1). Isso evidencia a existência de variabilidade genética entre as progênies quanto a esses caracteres, que pode ser utilizada de forma promissora na obtenção de ganhos via seleção para os tipos de inflorescência simples e composta. Entre os caracteres, a maior variabilidade em ordem decrescente foi observada para PG, NPV, COMPP e IG. Em outros estudos com genótipos de feijão-caupi de inflorescência simples, uma maior variabilidade também foi observada para PG (Lopes et al., 2001; Vidya et al., 2002; Rocha et al., 2003; Machado et al., 2008; Idahosa et al., 2010).

A estimativa de herdabilidade variou de média a alta para a maioria dos caracteres em ambos retrocruzamentos e tipos de inflorescência, exceto para o caractere IG, cujas estimativas foram baixas nos dois tipos de inflorescência, no $\mathrm{RC} 1$, e intermediárias no RC2 (Tabela 1). A prevalência do componente genético 
na expressão da maioria dos caracteres indica que há grandes possibilidades de ganhos com a seleção em futuras gerações.

As estimativas encontradas para o caractere IG, em ambos os retrocruzamentos, foram mais baixas que as estimativas de herdabilidade obtidas por Teixeira et al. (2007) e Andrade et al. (2010), de 0,8581 e
0,9056, respectivamente, em estudos conduzidos com genótipos de inflorescência simples.

Os caracteres COMPV, P100G, COMPP, NGV e PG avaliados nos dois retrocruzamentos, COMPP no RC1 e FI no RC2, apresentaram herdabilidades altas; a herdabilidade dos caracteres FI, no RC1, e NVP e NPV, no RC2, foram intermediárias (Tabela 1). De acordo com Sousa (2008), para caracteres que apresentam

Tabela 1. Estimativas de variâncias genéticas $\left(\sigma_{\mathrm{g}}^{2}\right)$, herdabilidades $\left(\mathrm{h}_{\mathrm{m}}^{2}\right)$ e médias fenotípicas $(\mu)$ em progênies $\mathrm{F}_{4}$ de feijãocaupi de inflorescência simples e composta oriundas dos retrocruzamentos RC1 e RC2.

\begin{tabular}{|c|c|c|c|c|c|}
\hline \multirow[t]{2}{*}{ Caractere $^{(1)}$} & \multirow[t]{2}{*}{ Inflorescência } & \multicolumn{3}{|c|}{ Parâmetros genéticos } & \multirow[t]{2}{*}{ Teste $\mathrm{t}$} \\
\hline & & $\mathrm{h}_{\mathrm{m}}^{2}(\mathrm{IC} 95 \%)$ & $\mathrm{h}_{\mathrm{m}}^{2}$ & $\mu$ & \\
\hline & & \multicolumn{4}{|c|}{ RC1, [(TV x 5058-09C) x Cacheado-roxo] x (TV x 5058-09C) } \\
\hline \multirow[t]{2}{*}{ COMPP } & Simples & $31,683(19,032 ; 62,977)$ & 0,8264 & 27,04 & $3,40^{*}$ \\
\hline & Composta & $68,475(42,863 ; 126,550)$ & 0,9114 & 33,26 & \\
\hline \multirow[t]{2}{*}{ COMPV } & Simples & $2,255(1,345 ; 4,540)$ & 0,8135 & 15,32 & $1,86^{\text {ns }}$ \\
\hline & Composta & $2,4113(1,4458 ; 4,8093)$ & 0,8235 & 14,55 & \\
\hline \multirow[t]{2}{*}{ FI } & Simples & $1,0441(0,4405 ; 4,8152)$ & 0,4464 & 43,91 & $14,45^{*}$ \\
\hline & Composta & $3,9993(2,3033 ; 8,6009)$ & 0,7554 & 50,76 & \\
\hline \multirow[t]{2}{*}{ IG } & Simples & $22,0135(11,4545 ; 58,4086)$ & 0,2965 & 67,64 & $1,95^{\text {ns }}$ \\
\hline & Composta & $19,9469(10,1359 ; 55,8504)$ & 0,2725 & 64,87 & \\
\hline \multirow[t]{2}{*}{ NGV } & Simples & $1,0278(0,5899 ; 2,2247)$ & 0,7518 & 7,68 & $2,80^{*}$ \\
\hline & Composta & $0,7318(0,3997 ; 1,7492)$ & 0,6832 & 6,93 & \\
\hline \multirow[t]{2}{*}{ NVP } & Simples & $0,02687(0,01459 ; 0,06498)$ & 0,6754 & 1,80 & $5,20^{*}$ \\
\hline & Composta & $0,05660(0,03365 ; 0,1147)$ & 0,8142 & 2,09 & \\
\hline \multirow[t]{2}{*}{ NPV } & Simples & $442,24(259,31 ; 919,17)$ & 0,7844 & 77,36 & $0,26^{\mathrm{ns}}$ \\
\hline & Composta & $357,92(204,66 ; 780,47$ & 0,7466 & 75,94 & \\
\hline \multirow[t]{2}{*}{ P100G } & Simples & $7,1415(4,2303 ; 14,5638)$ & 0,8016 & 18,82 & $0,57^{\mathrm{ns}}$ \\
\hline & Composta & $6,4743(3,7986 ; 13,4406)$ & 0,7856 & 18,41 & \\
\hline \multirow[t]{3}{*}{ PG } & Simples & $10.216(5838,39 ; 22.301)$ & 0,7437 & 264,61 & $1,36^{\mathrm{ns}}$ \\
\hline & Composta & $7.678,51(4.190,17 ; 18.392)$ & 0,6856 & 301,61 & \\
\hline & & \multicolumn{4}{|c|}{ RC2, (AU94-MOB-816 x Cacheado-roxo) x AU94-MOB-816 } \\
\hline \multirow[t]{2}{*}{ COMPP } & Simples & $15,1131(8,6011 ; 33,2591)$ & 0,7493 & 30,21 & $3,84 *$ \\
\hline & Composta & $32,4152(19,8079 ; 62,4828)$ & 0,8650 & 35,23 & \\
\hline \multirow[t]{2}{*}{ COMPV } & Simples & $2,7011(1,6051 ; 5,4758)$ & 0,8121 & 16,05 & $2,54 *$ \\
\hline & Composta & $2,1894(1,2772 ; 4,5950)$ & 0,7779 & 14,97 & \\
\hline \multirow[t]{2}{*}{ FI } & Simples & $3,1612(1,8472 ; 6,6135)$ & 0,7786 & 43,20 & $12,68 *$ \\
\hline & Composta & $3,6852(2,1847 ; 7,5041)$ & 0,8039 & 49,61 & \\
\hline \multirow[t]{2}{*}{ IG } & Simples & $19,3978(9,9315 ; 53,3809)$ & 0,6084 & 67,29 & $0,79^{\text {ns }}$ \\
\hline & Composta & $8,5531(3,3403 ; 51,0273)$ & 0,4065 & 66,30 & \\
\hline \multirow[t]{2}{*}{ NGV } & Simples & $1,5187(0,8890 ; 3,1669)$ & 0,7852 & 8,15 & $1,78^{\text {ns }}$ \\
\hline & Composta & $1,0622(0,5947 ; 2,4147)$ & 0,7188 & 7,59 & \\
\hline \multirow[t]{2}{*}{ NVP } & Simples & $0,03057(0,01503 ; 0,09255)$ & 0,5756 & 1,76 & $6,64 *$ \\
\hline & Composta & $0,05798(0,03256 ; 0,1310)$ & 0,7201 & 2,18 & \\
\hline \multirow[t]{2}{*}{ NPV } & Simples & $356,73(204,41 ; 774,75)$ & 0,7611 & 69,19 & $2,44 *$ \\
\hline & Composta & $85,3499(35,2879 ; 419,66)$ & 0,4326 & 58,38 & \\
\hline \multirow[t]{2}{*}{ P100G } & Simples & $7,9882(4,7202 ; 16,3654)$ & 0,7986 & 20,46 & $0,91^{\mathrm{ns}}$ \\
\hline & Composta & $7,4012(4,3439 ; 15,3550)$ & 0,7860 & 19,77 & \\
\hline \multirow[t]{2}{*}{ PG } & Simples & $10.796(6.180,21 ; 23.491)$ & 0,7556 & 273,16 & $0,79^{\text {ns }}$ \\
\hline & Composta & $6.875,47(3.698,92 ; 16.967)$ & 0,6631 & 294,43 & \\
\hline
\end{tabular}

${ }^{(1)}$ COMPP, comprimento do pedúnculo; COMPV, comprimento de vagem; FI, floração inicial; IG, índice de grãos; NGV, número de grãos por vagem; NVP, número de vagens por pedúnculo; NPV, número de pedúnculos com vagem; P100G, peso de 100 grãos; e PG, produção de grãos. ns Não significativo. *Significativo pelo teste $\mathrm{t}$, a $5 \%$ de probabilidade. 
herdabilidades médias a baixas, recomenda-se que a seleção seja feita em gerações mais avançadas. Os caracteres COMPP, FI e NVP avaliados nos dois retrocruzamentos, e P100G, PG e COMPV no $\mathrm{RC} 1$ apresentaram maiores herdabilidades para a inflorescência composta, em comparação à simples, o que indica que o sucesso na obtenção de ganhos para esses caracteres via seleção será maior para as progênies de inflorescência composta.

As herdabilidades obtidas neste trabalho foram menores que as obtidas para os caracteres PG, por Teixeira et al. (2007), Salimath et al. (2007), Andrade et al. (2010) e Benvindo et al. (2010), e P100G por Rocha et al. (2003), Matos Filho et al. (2009) e Andrade et al. (2010); no entanto, foram similares às obtidas para os caracterees COMPP, por Rocha et al. (2009), COMPV, por Salimath et al. (2007), NGV, por Omoigui et al. (2006), e PG por Machado et al. (2008) e Dias (2009). Também foram maiores que as obtidas para os caracteres COMPP, por Lopes et al. (2001), COMPV, por Omoigui et al. (2006) e Mohammed et al. (2010), P100G, por Matos Filho et al. (2009), e PG por Rocha et al. (2003), Omoigui et al. (2007) e Andrade et al. (2010). Todos os experimentos foram conduzidos em genótipos com inflorescência simples.

As médias fenotípicas entre inflorescências simples e compostas diferiram para a metade dos caracteres $(p<0,05)$, sendo superiores nas progênies de inflorescência composta em ambos os retrocruzamentos para COMPP, FI e NVP, e para NVP no RC2 (Tabela 1). Foram observados valores significativamente maiores para as progênies de inflorescência simples apenas para o caractere COMPV no RC2. Esse contraste evidencia a existência de variabilidade genética para tipos de inflorescência, o que possibilitará ganhos em seleções futuras para esses caracteres, com maior probabilidade de sucesso para a inflorescência composta. Sousa (2008), ao estudar esses mesmos retrocruzamentos na geração $F_{1}$, com um maior número de progênies, encontrou diferenças significativas entre médias de progênies de inflorescência simples e médias de progênies de inflorescência composta somente para os caracteres FI, nos dois retrocruzamentos, e P100G no $\mathrm{RC} 1$.

Os desvios das médias das estimativas BLUPs foram maiores para os caracteres IG, NGV, NVP e PG, quando a seleção foi praticada nas cinco melhores progênies, em comparação à praticada nas 10 e 15 melhores progênies (Tabela 2). Os desvios foram positivos para estes caracteres no $\mathrm{RC} 1$ e no $\mathrm{RC} 2$, tanto nas progênies de inflorescência simples como nas de inflorescência composta, exceto para IG, em seleção praticada nas 15 melhores progênies de inflorescência composta. Nunes (2006) estimou o ganho genético para a produção de grãos em progênies $\mathrm{F}_{4: 6}$ de feijão-comum, por meio do procedimento BLUP, ao aplicar diferentes proporções

Tabela 2. Estimativas dos ganhos genéticos com base nos BLUPs das 5, 10 e 15 melhores progênies oriundas dos retrocruzamentos RC1 e RC2, para o caractere produção de grãos ${ }^{(1)}$.

\begin{tabular}{|c|c|c|c|c|c|c|c|c|c|c|}
\hline Inflorescência & NS & COMPP & COMPV & FI & IG & NGV & NVP & NPV & P100G & PG \\
\hline & \multicolumn{10}{|c|}{$\mathrm{RC} 1,[(\mathrm{TV} \times 5058-09 \mathrm{C}) \times$ Cacheado-roxo $] \times(\mathrm{TV} \times 5058-09 \mathrm{C})$} \\
\hline & 5 & $-0,04$ & 0,25 & $-0,17$ & 1,10 & 0,78 & 0,06 & 22,59 & $-1,63$ & 159,82 \\
\hline \multirow[t]{3}{*}{ Simples } & 10 & $-0,71$ & 0,14 & $-0,40$ & 1,50 & 0,47 & 0,05 & 16,66 & $-0,88$ & 107,94 \\
\hline & 15 & $-0,30$ & $-0,03$ & $-0,14$ & 1,19 & 0,32 & 0,05 & 13,39 & $-0,70$ & 75,81 \\
\hline & 5 & $-1,57$ & $-0,29$ & $-0,06$ & 2,77 & 0,58 & 0,22 & 9,56 & $-0,37$ & 92,96 \\
\hline \multirow[t]{4}{*}{ Composta } & 10 & $-0,58$ & 0,10 & $-0,63$ & 1,44 & 0,48 & 0,13 & 7,29 & $-0,21$ & 81,46 \\
\hline & 15 & 0,05 & $-0,17$ & $-0,53$ & 1,26 & 0,35 & 0,12 & 7,16 & $-0,67$ & 64,18 \\
\hline & \multicolumn{10}{|c|}{ RC2, (AU94-MOB-816 x Cacheado-roxo) x AU94-MOB-816 } \\
\hline & 5 & 4,97 & 0,82 & 1,18 & 2,21 & 1,36 & $-0,13$ & 17,93 & 0,11 & 154,65 \\
\hline \multirow[t]{3}{*}{ Simples } & 10 & 3,15 & 0,20 & 0,41 & 1,74 & 0,58 & $-0,06$ & 13,09 & 0,25 & 105,08 \\
\hline & 15 & 2,09 & $-0,08$ & 0,07 & 0,96 & 0,44 & $-0,01$ & 11,12 & $-0,37$ & 80,01 \\
\hline & 5 & 1,17 & 0,49 & 0,92 & 1,04 & 0,71 & 0,02 & 9,94 & 0,12 & 119,24 \\
\hline \multirow[t]{2}{*}{ Composta } & 10 & 2,17 & 0,64 & 1,06 & 0,42 & 0,45 & 0,03 & 5,84 & 0,50 & 80,45 \\
\hline & 15 & 1,78 & 0,54 & 0,75 & $-0,05$ & 0,23 & 0,03 & 3,90 & 0,22 & 55,25 \\
\hline
\end{tabular}

${ }^{(1)} \mathrm{NS}$, número de progênies selecionadas; COMPP, comprimento do pedúnculo; COMPV, comprimento de vagem; FI, floração inicial; IG, índice de grãos; NGV, número de grãos por vagem; NVP, número de vagens por pedúnculo; NPV, número de pedúnculos com vagem; P100G, peso de 100 grãos; e PG, produção de grãos. 
de selecionados $(1,5,10$ e $25 \%)$ na geração $F_{4: 5}$. Diferentemente dos resultados obtidos neste trabalho, o autor obteve estimativas de ganhos maiores quando a seleção recaiu sobre a maior percentagem de selecionados.

O caractere COMPP apresentou desvios negativos no RC1 e positivos no RC2; neste último, os desvios foram maiores nas progênies de inflorescência simples em comparação às de inflorescência composta (Tabela 2). O melhoramento moderno tem enfatizado a seleção de genótipos com pedúnculos mais curtos (Freire Filho et al., 2005; Machado et al., 2007; Sousa, 2008; Rocha et al., 2009). Com base nas médias apresentadas para COMPP pelas progênies de inflorescências simples e composta, em RC1 e RC2 (Tabela 1), e nos ganhos (Tabela 2), é possível obter maior sucesso na seleção de pedúnculos mais curtos por meio da seleção de progênies de inflorescência simples, resultantes do RC1. Conforme Sousa (2008), a obtenção de ganhos para pedúnculos curtos nas progênies de inflorescência composta é mais difícil, porque os genitores com inflorescência composta que participaram dos cruzamentos apresentavam pedúnculos compridos.

Para o caractere FI, todos os desvios foram negativos para o RC1 e positivos para o RC2 (Tabela 2). Os desvios negativos nas progênies de inflorescência composta, resultantes do RC1, são desejáveis para o melhoramento de feijão-caupi, aliado com inflorescência composta (Sousa, 2008), pois atualmente a prioridade na seleção é para maior precocidade (Freire Filho et al., 2005; Machado et al., 2008).

Na seleção de progênies com inflorescência composta, nos caracteres COMPV, IG e NGV, é desejável que o desvio das médias BLUP sejam positivos, já que estes caracteres são diretamente responsáveis pelo incremento na produção de grãos (Bezerra et al., 2001; Oliveira et al., 2006). Nos caracteres IG, NVP e P100G, a maioria dos desvios para inflorescência composta foi positivo, com exceção do resultante da seleção praticada nas 15 melhores progênies de inflorescência composta (Tabela 2). Lopes et al. (2001), ao estudar o ganho genético em linhagens de feijão-caupi de inflorescência simples, observaram que $\mathrm{P} 100 \mathrm{G}$ e COMPV corresponderam ao primeiro e terceiro caracteres com maiores ganhos entre os demais avaliados, e que houve baixo ganho genético para NGV.
No caractere NVP, os desvios BLUPs foram positivos e superiores, no $\mathrm{RC} 1$ e no $\mathrm{RC} 2$, para as progênies de inflorescência composta; porém, foram negativos no RC2 para as progênies de inflorescência simples (Tabela 2). Esse resultado é pertinente à tendência atual do melhoramento de aumentar o número de vagens por planta na seleção para genótipos de porte ereto e arquitetura mais compacta, e indica que será mais fácil obter genótipos com esse ideotipo nas progênies de inflorescência composta. Lopes et al. (2001) obtiveram o menor ganho genético para NVP, em comparação a outros 11 caracteres avaliados em um grupo de linhagens de feijão-caupi de inflorescência simples.

Os maiores ganhos genéticos foram obtidos nos caracteres NPV e PG, o que mostra que o melhoramento para o aumento do número de pedúnculos com vagens e a produção de grãos é possível em ambos os retrocruzamentos (Tabela 2). No entanto, há maior probabilidade de ganhos quando a seleção for praticada nas progênies resultantes do RC1 de inflorescência simples. Lopes et al. (2001) obtiveram o segundo maior ganho genético para o caractere $\mathrm{PG}$, em comparação à outros dez caracteres avaliados em um grupo de linhagens de feijão-caupi de inflorescência simples. Vidya et al. (2002), ao avaliar um grupo de genótipos de inflorescência simples da subespécie sesquipedalis, também encontraram maior ganho genético para o caractere PG. Sousa (2008), ao estudar progênies de feijão-caupi de inflorescência simples e composta, obteve resultados semelhantes ao deste trabalho em relação à superioridade das progênies de inflorescência simples sobre as de inflorescência composta, quanto ao NVP.

Em geral, os contrastes entre médias de progênies e as estimativas de ganhos genéticos indicam que as progênies de inflorescência simples apresentam comportamento médio similar às de inflorescência composta. Na seleção de progênies de inflorescência composta, um maior potencial genético foi apresentado pelo retrocruzamento RC2 em comparação ao RC1. Há perspectiva de obtenção de ganhos para alguns caracteres na seleção de progênies de inflorescência composta. Também se espera que essa característica possa ser transferida para cultivares comerciais e que, consequentemente, consiga-se elevar o patamar de produtividade do feijão-caupi (Freire Filho et al., 2009). 


\section{Conclusões}

1. As progênies de inflorescência simples apresentam potencial genético produtivo similar ao das progênies de inflorescência composta.

2. As progênies de inflorescência composta resultantes do retrocruzamento (AU94-MOB-816 x Cacheado-roxo) x AU94-MOB-816 são promissoras para aumentar os atuais níveis de produtividade do feijão-caupi.

\section{Agradecimentos}

À Embrapa Meio-Norte e aos funcionários do setor de feijão-caupi, pelo auxílio na implantação e na condução dos experimentos; e ao Conselho Nacional de Desenvolvimento Científico e Tecnológico, pela concessão da bolsa de apoio técnico.

\section{Referências}

ANDRADE, F.N.; ROCHA, M. de M.; GOMES, R.L.F.; FREIRE FILHO, F.R.; RAMOS, S.R.R. Estimativas de parâmetros genéticos em genótipos de feijão-caupi avaliados para feijão fresco. Revista Ciência Agronômica, v.41, p.253-258, 2010.

ARAÚJO, J.P.P. de; SANTOS, A.A. dos; CARDOSO, M.J.; WATT, E. Nota sobre a ocorrência de uma inflorescência ramificada em caupi Vigna unguiculata (L.) Walp. Subsp, unguiculata no Brasil. Revista Ciência Agronômica, v.12, p.187-198, 1981.

BENVINDO, R.N.; SILVA, J.A.L. da; FREIRE FILHO, F.R.; ALMEIDA, A.L.G. de; OLIVEIRA, J.T.S.; BEZERRA, A.A. de C. Avaliação de genótipos de feijão-caupi de porte semi-prostrado em cultivo de sequeiro e irrigado. Comunicata Scientiae, v.1, p.23-28, 2010.

BEZERRA, A.A. de C.; ANUNCIAÇÃO FILHO, C.J. da; FREIRE FILHO, F.R.; RIBEIRO, V.Q. Inter-relação entre caracteres de caupi de porte ereto e crescimento determinado. Pesquisa Agropecuária Brasileira, v.36, p.137-142, 2001.

DIAS, F.T.C. Utilização de técnicas multivariadas e moleculares na caracterização e seleção de genótipos de feijão-caupi de porte ereto e ciclo precoce. 2009. 99p. Dissertação (Mestrado) Universidade Federal do Ceará, Fortaleza.

FAWOLE, I.; AFOLABI, O. Genetic control of a branching peduncle mutant of cowpea, Vigna unguiculata (L.) Walp. Journal of Agricultural Science, v.100, p.473-475, 1983.

FREIRE FILHO, F.R.; ROCHA, M. de M.; DAMASCENO-SILVA, K.J.; RIBEIRO, V.Q.; NOGUEIRA, M.S.R. Feijão-caupi: melhoramento genético, resultados e perspectivas. In: SIMPÓSIO NORDESTINO DE GENÉTICA E MELHORAMENTO DE PLANTAS, 1., 2009, Fortaleza. Anais. Fortaleza: Embrapa Agroindústria Tropical, 2009. p.25-59.
FREIRE FILHO, F.R.; RIBEIRO, V.Q.; BARRETO, P.D.; SANTOS, A. dos. Melhoramento genético. In: FREIRE FILHO, F.R.; RIBEIRO, V.Q.; LIMA, J.A. de A. (Ed.). Feijão-caupi: avanços tecnológicos. Brasília: Embrapa Transferência de Tecnologia, 2005. p.29-92.

FREIRE FILHO, F.R.; ROCHA, M. de M.; RIBEIRO, V.Q.; SITOLLIN, I.M. Avanços e perspectivas para a cultura do feijão-caupi. In: ALBUQUERQUE, A.C.S.; SILVA, A.G. da (Ed.). Agricultura Tropical: quatro décadas de inovações tecnológicas, institucionais e políticas. Brasília: Embrapa Informação Tecnológica, 2008. v.1, p.285-250.

HENDERSON, C.R. Best linear unbiased estimation and prediction under a selection model. Biometrics, v.31, p.423-447, 1975.

IDAHOSA, D.O.; ALIKA, J.E.; OMOREGIE, A.U. Genotypic variability for agronomic and yield characters in some cowpea (Vigna unguiculata (L.) Walp.). Nature and Science, v.8, p.48-55, 2010.

LOPES, A.C. de A.; FREIRE FILHO, F.R.; SILVA, R.B.Q.; CAMPOS, F.L.; ROCHA, M. de M. Variabilidade entre caracteres agronômicos em caupi (Vigna unguiculata (L.) Walp.). Pesquisa Agropecuária Brasileira, v.36, p.515-520, 2001.

MACHADO, C. de F.; FREIRE FILHO, F.R.; RIBEIRO, V.Q.; COSTA, D.S.S.; AMORIM, A.F. de. Herança da inflorescência composta da cultivar de feijão-caupi cacheado. Ciência e Agrotecnologia, v.31, p.1347-1350, 2007.

MACHADO, C. de F.; TEIXEIRA, N.J.P.; FREIRE FILHO, F.R.; ROCHA, M. de M.; GOMES, R.L.F. Identificação de genótipos de feijão-caupi quanto à precocidade, arquitetura da planta e produtividade de grãos. Revista Ciência Agronômica, v.39, p.114-123, 2008.

MATOS FILHO, C.H.A.; GOMES, R.L.F.; ROCHA, M. de M.; FREIRE FILHO, F.R.; LOPES, A.C. de A. Potencial produtivo de progênies de feijão-caupi com arquitetura ereta de planta. Ciência Rural, v.39, p.348-354, 2009.

MOHAMMED, M.S.; RUSSOM, Z.; ABDUL, S.D. Inheritance of hairiness and pod shattering, heritability and correlation studies in crosses between cultived cowpea (Vigna unguiculata (L.) Walp.) and its wild (Var. pubescens) relative. Euphytica, v.171, p.48-55, 2010.

NAKAMAE, I.J. AGRIANUAL 2004: anuário da agricultura brasileira. São Paulo: FNP consultoria \& Comércio, 2004. 496p.

NUNES, J.A.R. Incorporação da informação de parentesco no método genealógico pelo enfoque de modelos mistos. 2006. 113p. Tese (Doutorado) - Universidade Federal de Lavras, Lavras.

OLIVEIRA, F.J.; ANUNCIAÇÃO FILHO, C.J. da; BASTOS, G.Q.; REIS, O.V.; TEÓFILO, E.M. Caracteres agronômicos aplicados na seleção de cultivares de caupi. Revista Ciência Agronômica, v.34, p.44-50, 2006.

OMOIGUI, L.O.; ISHIYAKU, M.F.; KAMARA, A.Y.; ALABI, S.O.; MOHAMMED, S.G. Genetic variability and heritability studies of some reproductive traits in cowpea (Vigna unguiculata (L.) Walp.). African Journal of Biotechnology, v.15, p.1191-1195, 2006. 
PATTERSON, H.D.; THOMPSON, R. Recovery of inter-block information when block sizes are unequal. Biometrika, v.58, p.545-554, 1971.

RAMALHO, M.A.P.; FERREIRA, D.F.; OLIVEIRA, A.C. Experimentação em genética e melhoramento de plantas. 2.ed. Lavras: UFLA, 2005. 326p.

RESENDE, M.D.V. Efeitos fixos ou aleatórios de repetições no contexto dos modelos misto no melhoramento de plantas perenes. Colombo: Embrapa Florestas, 2002. 15p. (Embrapa Floresta. Documentos, 68).

ROCHA, M. de M.; CAMPELO, J.E.G.; FREIRE FILHO, F.R.; RIBEIRO, V.Q.; LOPES, A.C. de A. Estimativas de parâmetros genéticos em genótipos de feijão-caupi de tegumento branco. Revista Científica Rural, v.8, p.135-141, 2003.

ROCHA, M. de M.; CARVALHO, K.L.M.; FREIRE FILHO, F.R.; LOPES, A.C. de A.; GOMES, R.L.F.; SOUSA, I.S. Controle genético do comprimento do pedúnculo em feijão-caupi. Pesquisa Agropecuária Brasileira, v.44, p.270-275, 2009.

SALIMATH, P.M.; LINGANAGOWDA, S.B.; UMA, M.S. Variability parameters $F_{2}$ and $F_{3}$ populations of cowpea involving determinate, semideterminate and indeterminate types. Karnataka Journal of Agricultural Science, v.20, p.255-256, 2007.
SAS INSTITUTE.SAS/STAT software: changes and enhancements through release. Version 8.02. Cary: SAS Institute, 1999.

SATTERTHWAITE, F.E. An approximate distribution of estimates of variance components. Biometrics Bulletin, v.2, p.110-114, 1946.

SEN, N.K.; BHOWAL, J.G. Genetics of Vigna sinensis (L.) Savi. Genetica, v.32, p.247-266, 1961.

SOUSA, I.S. Herança do comprimento do pedúnculo ramificado em feijão-caupi e sua relação com a produtividade e seus componentes. 2008. 89p. Dissertação (Mestrado) - Universidade Federal Rural de Pernambuco, Recife.

TEIXEIRA, N.J.P.; MACHADO, C.F.; FREIRE FILHO, F.R.; ROCHA, M. de M.; GOMES, R.L.F. Produção, componentes de produção e suas inter-relações em genótipos de feijão-caupi (Vigna unguiculata (L.) Walp.) de porte ereto. Revista Ceres, v.54, p.374-382, 2007.

TIMKO, M.P.; SINGH, B.B. Cowpea, a multifunctional legume. In: MOORE, P.H.; MING, R. (Ed.). Genomics of tropical crop plants. New York: Springer, 2008. p.227-258.

VIDYA, C.; OOMMEN, S.K.; KUMAR, V. Genetic variability and heritability of yield and related characters in yard-long bean. Journal of Tropical Agriculture, v.40, p.11-13, 2002.



